\section{Adaptação transcultural do Female Sexual Function Index}

\author{
Cross-cultural adaptation of the Female Sexual \\ Function Index
}

\footnotetext{
1 Faculdade de Medicina de Ribeirão Preto, Universidade de São Paulo, Ribeirão Preto, Brasil.

2 Instituto Paulista de Sexualidade, São Paulo, Brasil.

3 Centro de Estudos e

Pesquisas do Comportamento e Sexualidade, São Paulo, Brasil.

Correspondência E. M. Vieira

Departamento de Medicina Social, Faculdade de Medicina de Ribeirão Preto, Universidade de São Paulo. Av. dos Bandeirantes 3900 , 2 o andar, Ribeirão Preto, $S P$ 14049-900, Brasil.

bmeloni@fmrp.usp.br
}

\section{Abstract}

The epidemiology of female sexual dysfunctions is still not well known. The Female Sexual Function Index (FSFI) is a short questionnaire specially designed to assess female sexual response. This study aimed to evaluate the cross-cultural equivalence of the Portuguese version of the FSFI. The cross-cultural adaptation involved five steps: translation, back-translation, formal equivalence assessment, review by specialists in sexuality, and pre-testing. After identification of semantic problems, agreements, and disagreements, a brief version was proposed, selecting and incorporating items from one of the two Portuguese versions. Some changes were made after pre-testing the questionnaire, most of which to make the Portuguese version more readily comprehensible and acceptable for the target population, using ordinary words as options or to complement the scientific language. Comparing more than one version of the instrument in the process of cross-cultural equivalence allowed detecting problems and difficulties in adapting the language, which would not have been observed otherwise.

Physiological Sexual Dysfunction; Women's Health; Questionnaires
Rodolfo de Carvalho Pacagnella 1

Elisabeth Meloni Vieira 1

Oswaldo Martins Rodrigues Jr. 2

Claudecy de Souza 3

\section{Introdução}

No século XX, o comportamento sexual tornouse objeto de estudo empírico, afastando-se da classificação nosológica médica de crimes e perversões sexuais que abundaram no século anterior. Um desses marcos são os estudos de Kinsey, que na década de 1950 promovem essa ruptura ao desenvolver inquéritos populacionais sobre comportamento sexual na população geral, deixando assim de lado a idéia de "desvios sexuais" 1. No Brasil, as pesquisas sobre comportamento sexual sofrem um incremento e interesse especialmente após o advento da AIDS. As mudanças sociais advindas após essa epidemia mobilizaram a comunidade acadêmica e se tornaram prioridade de pesquisa no campo sócio-antropológico 2.

Nesse aumento do interesse pelo tema, porém, prevaleceu, até o momento, o enfoque na sexualidade masculina 3 . A maior disponibilidade de tratamentos para disfunção erétil com intensa exposição da disfunção sexual masculina aumentou a procura de homens por consulta e tratamento, o que abriu caminho também para discussão da sexualidade feminina ${ }^{4}$. Contudo, embora haja cada vez mais estudos, ainda hoje pouco se conhece sobre a epidemiologia das disfunções sexuais femininas 5,6, e poucos tratamentos estão disponíveis para as mulheres em comparação com os homens ?. 
Uma das barreiras para o desenvolvimento desses estudos é a falta de consenso sobre o modelo ou paradigma para a compreensão da resposta sexual feminina ${ }^{4}$. Novos modelos não lineares recentemente propostos contestam o modelo de Masters \& Johnson ${ }^{8}$, que propunham um ciclo de resposta sexual em seqüência definida e linear constituído por quatro fases comuns para ambos os sexos: o estímulo sexual provocaria excitação fisiológica e, havendo continuidade na estimulação, o nível de tensão aumentaria atingindo-se um platô da excitação podendo-se em seguida chegar à fase de orgasmo, após o qual haveria um período de resolução, refratário a um novo estímulo sexual, com retorno do corpo a uma fase pré-excitatória.

Os novos modelos sugerem que possivelmente a resposta sexual não seja comum a ambos os sexos ${ }^{9}$, pois para a mulher haveria um componente subjetivo. Se o estímulo é visto potencialmente como positivo, a estimulação é desfrutada; se é visto potencialmente como negativo, culpa, vergonha, embaraço ou medo são disparados. De fato, essas inter-relações foram observadas em estudos de validação de questionários e podem ser tomadas como evidência da natureza multifatorial das disfunções sexuais femininas 10. Além disso, não há uma classificação diagnóstica amplamente aceita e as que existem atualmente não avaliam conjuntamente os aspectos subjetivos e objetivos da resposta sexual das mulheres 4 , mas há alguns anos o refinamento da classificação diagnóstica das disfunções sexuais femininas vem sendo objeto de estudo 7,11 .

Até então, as medidas das alterações fisiológicas desempenharam importante papel na avaliação da função sexual ${ }^{6}$. Os métodos diretos de medida da resposta sexual humana, no entanto, perdem em praticidade e não são capazes de avaliar as questões subjetivas envolvidas 12,13. Ademais, as sensações físicas da resposta sexual feminina, mesmo quando conscientemente percebidas, nem sempre se traduzem em experiência sexual subjetiva 14,15.

Na prática clínica, as entrevistas estruturadas e abertas e inventários 16 oferecem o melhor instrumento e método de avaliação dos componentes da função sexual. Todavia, para alguns autores 17 , a forma mais adequada de se avaliar a função sexual em mulheres seria no contexto natural com questionários desenvolvidos particularmente para essa finalidade. Para Ciconelli 18, os questionários transformam medidas subjetivas em dados objetivos, quantificáveis e analisáveis de forma global ou específica. Recente consenso recomenda o processo de padronização e validação de questionários para a avaliação da função e resposta sexual feminina 7 .
Atualmente, grande variedade de questionários tem sido desenvolvida para avaliar a função sexual de homens e mulheres. Questionários breves e auto-aplicados 18,19,20,21, assim como diários e registros de eventos 18,20,21, são usados em larga escala em estudos clínicos. Para Althof et al. ${ }^{4}$, os homens têm a capacidade de relatar com facilidade a ocorrência e a característica da ereção, e isso seria a base dos estudos que utilizam essa metodologia de registrar os eventos sexuais diariamente. Porém, segundo esse autor, isso não pode ser considerado em relação à excitação feminina, que é de difícil caracterização e apresenta importante componente subjetivo.

Para alguns autores 17, os instrumentos mais adequados para se avaliar a função sexual feminina, considerando-se a característica subjetiva da resposta sexual feminina seriam os questionários auto-aplicados, que avaliam vários domínios no campo da sexualidade e apresentam alto grau de confiabilidade e validade. Dentre os mais estudados atualmente estão o Brief Sexual Function Index for Women e o Female Sexual Function Index (FSFI; http://www.fsfi.questionnaire.com) [Índice de Função Sexual Feminina]. Tais instrumentos seriam também sensíveis para avaliar intervenções 6 . Alguns autores 21, comparando a pletismografia vaginal, registro de eventos e o FSFI concluíram que este último foi o único instrumento capaz de predizer melhora após o tratamento.

Outra característica importante dos questionários auto-aplicados refere-se à escala de resposta que utilizam, pois são delineados para utilizar a escala ordinal e de intervalo, com a capacidade de detectar diferenças sutis em um nível sofisticado de medida. Ao contrário, os diários e calendários de eventos utilizam uma escala nominal que não permite obter nuances sutis nas informações sobre o objeto de estudo 4 .

No Brasil, alguns autores 22 desenvolveram um instrumento com o objetivo de avaliar ampla e detalhadamente hábitos, tendências e práticas sexuais da população brasileira. Eles propõem um questionário simplificado para detectar possíveis portadores de dificuldades sexuais de diferentes níveis, entretanto o instrumento não se restringe à avaliação dos domínios da função sexual, mas pesquisa outros aspectos do comportamento sexual.

Para Rosen et al. 17, problemas que afetam um domínio da resposta sexual humana podem interagir com outras desordens de uma forma complexa, resultando potencial viés na categorização das disfunções. Assim, há necessidade de instrumentos capazes de avaliar a relativa força da disfunção em cada domínio. 
Um instrumento que congrega as características de ser prático para aplicação em estudos de campo, avaliar a força relativa de cada domínio da resposta sexual feminina e transformar medidas subjetivas em dados objetivos, quantificáveis e analisáveis, é o FSFI 17, validado para a população de língua inglesa 10,23 e projetado para ser um instrumento de avaliação em estudos epidemiológicos que respeitam a natureza multidimensional da função sexual feminina. O objetivo do instrumento é ser sumário, válido e seguro na avaliação da função sexual feminina 17. Alguns ainda apóiam o uso do FSFI como uma ferramenta de triagem: poucos questionários foram validados em amostras de múltiplas disfunções e, além disso, nenhum ponto de corte foi desenvolvido ou validado para qualquer dos questionários existentes 10,23.

O FSFI é um questionário desenvolvido para ser auto-aplicado, e que se propõe avaliar a resposta sexual feminina nos domínios (fases ou componentes da resposta sexual): desejo sexual, excitação sexual, lubrificação vaginal, orgasmo, satisfação sexual e dor 6,17. Para isso, são apresentadas dezenove questões que avaliam a função sexual nas últimas quatro semanas e apresentam escores em cada componente. Para cada questão existe um padrão de resposta. As opções de respostas recebem pontuação entre 0 a 5 de forma crescente em relação à presença da função questionada. Apenas nas questões sobre dor a pontuação é definida de forma invertida. Deve-se notar que, se o escore de algum domínio for igual a zero, isso significa que não foi referida pela entrevistada relação sexual nas últimas quatro semanas. Ao final é apresentado um escore total, resultado da soma dos escores de cada domínio multiplicada por um fator que homogeneíza a influência de cada domínio no escore total (Tabela 1). Assim, para se chegar ao escore total deve-se proceder à soma dos valores das questões, multiplicar essa soma pelo fator de correção e, então, somar os valores de cada domínio. No desenvolvimento do instrumento original, os autores propuseram essa forma de homogeneizar a influência de cada domínio no escore total, baseando-se em um algoritmo computacional simples 17. Caso não houvesse o fator de multiplicação, os domínios participariam com pesos diferentes na composição do escore total.

Com base no valor do escore total, seria possível discriminar entre as populações com maior e menor risco de apresentar disfunção sexual 10 .

O presente estudo teve por objetivo avaliar a equivalência semântica entre os itens constituintes do instrumento e o FSFI original em inglês e propor uma versão final. Além disso, foram avaliados outros aspectos da adaptação transcultural como equivalência idiomática, cultural, conceitual e de pontuação entre a versão original e a versão final.

\section{Método}

Antes da adaptação transcultural obteve-se a autorização do pesquisador principal que elaborou o instrumento 17 . O processo de avaliação de equivalência semântica foi desenvolvido segundo Guillemin et al. ${ }^{24}$ e estudos similares $25,26,27,28,29,30$. A este modelo acrescentou-se a etapa de apreciação formal de equivalência semântica realizada por Reicheinhem et al. 26 . O estudo envolveu cinco etapas: tradução, retrotradução, apreciação formal de equivalência semântica, crítica final por especialistas com avaliação de outros aspectos além da questão semântica e pré-teste do instrumento com incorporação de pequenas modificações.

Escores de avaliação do Female Sexual Function Index.

\begin{tabular}{lcccc}
\hline Domínio & Questões & Variação do escore & Fator de multiplicação & Escore mínimo \\
\hline Desejo & 1,2 & $1-5$ & 0,6 & 1,2 \\
Excitação & $3,4,5,6$ & $0-5$ & 0,3 & 0 \\
Lubrificação & $7,8,9,10$ & $0-5$ & 0,3 & 0 \\
Orgasmo & $11,12,13$ & $0-5$ & 0,4 & 0 \\
Satisfação & $14,15,16$ & 0 (ou 1)-5* & 0,4 & 0,8 \\
Dor & $17,18,19$ & $0-5$ & 0,4 & 6 \\
\hline
\end{tabular}

* Questão 14 varia de 0,0 a 5,0. Questões 15 e 16 variam de 1,0 a 5,0. 
Consistiu de duas traduções independentes do instrumento original (inglês) para o português. A primeira tradução (T1) foi feita por um grupo de profissionais com experiência na área de sexualidade humana e fluência em inglês. Um profissional de nível superior formado em tradução (tradutor juramentado) procedeu à segunda tradução (T2).

\section{Etapa 2}

As traduções T1 e T2 foram retrotraduzidas para o inglês de forma independente por dois tradutores juramentados (R1 e R2).

\section{Etapa 3}

A avaliação da equivalência semântica foi realizada por um profissional com formação em Letras e especialização em inglês, diferente dos envolvidos nas Etapas 1 e 2. Duas questões foram apreciadas:

- O significado referencial dos termos/palavras constituintes: representa as idéias ou objetos do mundo a que uma única palavra ou um conjunto de palavras se refere. Assume-se que existe uma correspondência literal entre os termos e se o significado referencial é o mesmo no original e na respectiva versão 28 .

- O significado geral de cada pergunta, instrução ou opção de resposta. Esta correspondência vai além do significado literal de termos e leva em consideração seu impacto no contexto cultural da população-alvo ${ }^{28}$. A avaliação é importante porque, mesmo que haja correspondência literal, não significa que haja uma mesma significação subjetiva em culturas diferentes.

Os três formulários foram submetidos à apreciação; dois formulários continham perguntas, instruções ou opções de resposta do original, posicionadas lado a lado das duas versões. Um terceiro formulário continha pares com as assertivas das retrotraduções, que serviu como estratégia de mascaramento.

Na parte usada para apreciar o significado referencial, a equivalência entre pares de assertivas foi avaliada numa escala analógico-visual, contínua, entre $0 \%$ e $100 \%$. Na avaliação do significado geral, utilizou-se uma avaliação qualitativa em quatro níveis: inalterado (IN), pouco alterado (PA), muito alterado (MA) ou completamente alterado (CA).

\section{Etapa 4}

Três juízes com fluência nos dois idiomas e experiência na área temática participaram do processo no qual se realizou uma crítica das etapas anteriores. A partir da identificação dos problemas e discordâncias entre as duas retrotraduções foi proposta uma versão sintética, escolhendo e incorporando itens de cada uma. O objetivo da equipe foi escolher a melhor forma de se expressar o mesmo conceito de cada sentença simultaneamente nas duas línguas. Além do mais, procurou-se eliminar ambigüidades e redundâncias. Essa etapa foi também responsável por avaliar outros aspectos além da equivalência semântica. Foram verificadas ainda a equivalência idiomática - relativa às expressões próprias do idioma e coloquiais -, a equivalência cultural ou experimental - se as situações evocadas na cultura de origem do instrumento têm a mesma referência na cultura de destino -, a equivalência conceitual - a manutenção da validade na versão final do mesmo conceito explorado na versão original -, e a equivalência de pontuação - da forma de pontuação da versão final em comparação com a versão original.

\section{Etapa 5}

Pré-teste do instrumento: foram entrevistadas dez mulheres com idade entre 20 e 44 anos (mediana 32 anos) recrutadas no ambulatório de ginecologia de uma unidade básica de saúde. As entrevistas ocorreram ao final da consulta médica de retorno, cuja anamnese contempla questões sobre a função sexual das pacientes. Após a abordagem, o questionário foi aplicado face a face no consultório médico por ginecologista àquelas que aceitaram participar da entrevista. Ao final da entrevista, as mulheres foram perguntadas sobre a clareza das perguntas do questionário da seguinte forma: "Existe alguma palavra ou questão que eu lhe disse e que você não entendeu, não conhece ou gostaria de perguntar?". Além dessa resposta foi anotado o tempo de duração da entrevista - que variou entre 8 e 23 minutos (média 14,2 minutos).

Após o pré-teste do questionário, outras modificações foram realizadas. A maioria pretendeu tornar a versão em português mais coloquial e aceitável para a população alvo e envolveu a substituição de pronomes e a utilização de termos mais corriqueiros em nosso meio. Em algumas situações, as modificações visaram ampliar a equivalência de significado geral dos termos. 


\section{Resultados}

A avaliação do processo e a revisão bibliográfica sugerem que os conceitos utilizados na versão original do instrumento eram adequados ao contexto cultural brasileiro. Porém, optou-se por adaptar algumas palavras para oferecer mais clareza dos termos utilizados.

De forma geral, as duas versões mostraramse semelhantes. De 32 itens de assertivas (instruções, questões e respostas), 20 eram similares segundo a Etapa 3 do processo. Dos 12 itens que apresentaram divergências na avaliação do significado geral e referencial, alguns pares de assertivas apresentaram grande divergência. Nas instruções, ambas retrotraduções da definição de ato sexual (sexual intercourse) receberam pontuação MA e 40 na avaliação do significado geral e referencial, respectivamente. A mesma situação ocorreu na comparação da opção de resposta da Questão 1. Outros pares de assertivas que apresentaram divergência na comparação foram: Questão 2, que recebeu notas MA e 60 na R2 e IN e 100 na R1; Questão 4, com notas MA e 60 na R1 e IN e 100 na R2; opção de resposta da Questão 5, com notas CA e 0 na R2 e IN e 100 na R1; opção de resposta da Questão 13 com notas PA e 80 na avaliação dos significados geral e referencial na R1 e IN e 100 na R2.

Os demais pares receberam notas PA para significado geral e notas entre 60 e 80 no significado referencial. Quando houve discordância entre as retrotraduções quanto ao significado referencial ou geral, optou-se pela de maior pontuação. No entanto, quando não houve discordância, essa escolha foi feita segundo julgamento dos juízes, levando-se em conta aspectos estilísticos e de clareza dos termos, optando-se ora por uma tradução, ora por outra e ora se modificando ou mesclando termos similares nas duas traduções.

A avaliação da Etapa 4 objetivou ainda, conforme sugerem Guillemin et al. ${ }^{28}$, avaliar as equivalências idiomática, cultural, conceitual e de pontuação entre a versão original e a versão final para montar a versão final com sentenças curtas, evitando-se o uso de pronomes, voz passiva, metáforas e palavras de significado amplo ou vago. Como no caso da tradução de sexual intercourse, em que se optou pelo termo ato sexual. Entende-se que "relação sexual" seja percebida pelos brasileiros como algo além do ato da penetração vaginal. Assim, ato sexual seria o mais próximo da definição utilizada pelo instrumento original, que o define como: quando há penetração do pênis na vagina.

Da mesma forma, a expressão carícias preliminares foi preferida em relação ao termo jogos amorosos preliminares, visto que este último pode não ser entendido como estimulação erótica. Na definição de estímulos sexuais, optou-se por modificar a tradução feita pelo tradutor (T2) e introduzir a palavra pensamentos entre parênteses a fim de diferenciar o termo fantasia sexual de objeto de fetiche sexual.

Na definição de desejo sexual, a comparação semântica mostrou-se mais adequada na tradução realizada pelos profissionais da área (T1), entretanto a definição foi adaptada ao se substituírem os termos do parceiro por de um parceiro(a). A modificação foi proposta por se observar que na língua inglesa não há definição de gênero na palavra partner, dessa forma, traduzindo-se apenas por parceiro poderíamos excluir da definição os estímulos homossexuais.

Sobre a definição de excitação sexual, a tradução literal de tingling por formigamento oferecia uma idéia de parestesia ou dormência nos genitais, o que não era a intenção original do instrumento, assim foi proposta a substituição pela palavra swelling (inchaço).

\section{Nas perguntas}

Substituições semelhantes às realizadas nos termos da introdução foram realizadas nas perguntas, assim, o termo sexual intercourse foi substituído pelo termo ato sexual nas Questões 3, 4, 5, $6,7,8,9,10,11,12$ e 13. A modificação dos termos parceiro por parceiro(a) também foi proposta nas Questões 14 e 15.

Notou-seinicialmentequeaescaladefreqüência de respostas utilizadas nas Questões 1, 3, 6, 7, 11, 17 e 18 apresentava algumas dificuldades nas traduções. A dificuldade principal foi combinar a noção de quantas vezes (ocasiões individuais) com a noção de tempo (período global). Para facilitar a compreensão, optou-se por introduzir entre parênteses a expressão quantas vezes após a palavra freqüência.

Para a tradução da palavra level, optou-se por grau, pois esta palavra oferece melhor significado de divisões de uma escala de medidas que a palavra nível. Essa modificação foi proposta nas Questões 2, 4, 5 e 19.

Na Questão 5, a palavra confident foi mais bem traduzida por segurança do que por convicção. Tal escolha se originou da comparação entre as retrotraduções em inglês, mas a palavra segurança também oferece idéia de confiança em si mesmo, o que se aproxima mais da idéia proposta pelo texto original.

Nas Questões 8, 10, 12, 13, 14, 15 e 16, optouse por não utilizar a palavra quão, que por ser menos coloquial e poderia ser de difícil entendimento para as camadas menos instruídas da 
população; desse modo, nessas questões foram utilizadas expressões equivalentes (qual foi, $o$ quanto).

A substituição da expressão estimulação sexual por estímulo sexual foi realizada nas Questões 11 e 12 por oferecer a forma mais adequada em relação às instruções iniciais.

Na Questão 19, a palavra rate traduzida por classificar ofereceu a melhor comparação entre as traduções e o texto original.

\section{Nas respostas}

Da mesma forma que nas Questões 1, 3, 6, 7, 11, 17 e 18, um grupo de respostas apresentava algumas dificuldades nas traduções referentes à escala de freqüência. No original, a palavra times é colocada na sentença (o que pode ser traduzido por vezes) e time entre parênteses (o que pode ser traduzido por tempo). Como nenhuma das versões contemplou essa nuance, modificou-se a versão final e se incluiu a palavra "tempo", já que nas questões relativas ao desejo sexual não se avalia o desejo em relação a um evento específico, mas em relação ao tempo.

No grupo de respostas da Questão 5, manteve-se o mesmo padrão da pergunta ao se traduzir confident por segurança, e da mesma forma, a tradução da palavra slightly por ligeiramente foi a melhor opção encontrada no grupo de respostas das Questões 8,10 e 12.

\section{Inclusão de termos corriqueiros da linguagem popular}

A partir do pré-teste do questionário, alguns termos corriqueiros da linguagem foram incluídos na versão final com a pretensão de facilitar o entendimento. Essa inclusão se fundamentou em outros estudos 22 e não substitui a linguagem técnico-científica, mas coloca no questionário uma opção para substituir o termo técnico pela linguagem popular em caso de não-entendimento do primeiro. Para masturbação, incluiu-se a sinonímia popular "punheta" ou "siririca". Da mesma forma, para lubrificação vaginal foram acrescentados os sinônimos "vagina molhada" e "tesão vaginal", e para orgasmo foi incluída a expressão "gozar". O uso da palavra "tesão" foi evitado, pois poderia ter como sinônimos, tanto desejo como excitação ou prazer sexual, o que poderia trazer mais confusão que clareza. A versão finalizada da tradução para o português encontra-se apresentada na Tabela 2.

\section{Discussão}

No campo da sexualidade busca-se desenvolver instrumentos para avaliação da função sexual com finalidade de transformar medidas subjetivas em dados objetivos 18. Basson et al. 7, em recente consenso sobre disfunção sexual feminina, recomendam a padronização e a validação desses instrumentos. Entretanto, a maior parte dos questionários desenvolvidos para avaliação da função sexual foi formulada na língua inglesa e direcionada para a população que fala esse idioma.

Em virtude do crescente número de ensaios multicêntricos, faz-se necessária a padronização e tradução desses instrumentos para sua aplicação em outras populações cujo idioma não seja o inglês. O processo, porém, vai além de uma simples tradução, é necessário um rigoroso processo de adaptação cultural do instrumento para que ele possa reproduzir suas características em uma cultura diferente. Ainda que seja possível argumentar que o questionário apresente conceitos genuinamente universais para a sociedade ocidental, há nuances e características peculiares a cada população que devem ser respeitadas 25 .

Nesse sentido, existe grande discussão na literatura sobre os métodos apropriados para se realizar adaptações transculturais de instrumentos de avaliação da qualidade de vida. Alguns autores $24,27,28$ iniciaram essa discussão e trouxeram à baila questões sobre a confusão terminológica e uma real carência de sistemática na avaliação de equivalência transcultural entre instrumentos desenvolvidos em determinado idioma e sua(s) versão(ões) 27. O grande questionamento seria quanto ao comprometimento da validade da informação, fato que levaria à perda das características originais do instrumento. Por isso alguns autores oferecem instruções padronizadas que tentam minimizar essas perdas decorrentes da mudança do idioma 24,25,26,27,28,29.

Assim, o presente trabalho considerou esses aspectos e se orientou pelo modelo sugerido por Guillemim et al. 28 no desenvolvimento da versão em português do FSFI. Nesse processo, algumas das dificuldades foram semelhantes às encontradas na tradução para o português do International Index of Erectile Function 29, sobretudo em relação à escala de freqüências utilizada em algumas questões com a inclusão da expressão "quantas vezes" após a expressão "com que freqüência” a fim de facilitar a compreensão.

À guisa do observado por outros autores 25,26,30, foi grande a importância da etapa de julgamento por comitê na elaboração da versãosíntese. Nessa etapa, verificou-se que, ao se confrontar mais de uma versão do instrumento, foi 
Versão final do Female Sexual Function Index em português.

\section{Perguntas}

1- Nas últimas 4 semanas com que freqüência (quantas vezes) você sentiu desejo ou interesse sexual?

2- Nas últimas 4 semanas como você avalia o seu grau de desejo ou interesse sexual?

3- Nas últimas 4 semanas, com que freqüência (quantas vezes) você se sentiu sexualmente excitada durante a atividade sexual ou ato sexual?

4- Nas últimas 4 semanas, como você classificaria seu grau de excitação sexual durante a atividade ou ato sexual?

5- Nas últimas 4 semanas, como você avalia o seu grau de segurança para ficar sexualmente excitada durante a atividade sexual ou ato sexual?

6- Nas últimas 4 semanas, com que freqüência (quantas vezes) você ficou satisfeita com sua excitação sexual durante a atividade sexual ou ato sexual?

7- Nas últimas 4 semanas, com que freqüência (quantas vezes) você teve lubrificação vaginal (ficou com a "vagina molhada") durante a atividade sexual ou ato sexual?

8- Nas últimas 4 semanas, como você avalia sua dificuldade em ter lubrificação vaginal (ficar com a "vagina molhada") durante o ato sexual ou atividades sexuais?

\section{Opções de respostas e}

pontuação

\section{5 = Quase sempre ou sempre}

4 = A maioria das vezes (mais do que a metade do tempo)

3 = Algumas vezes (cerca de metade do tempo)

2 = Poucas vezes (menos da metade do tempo)

$1=$ Quase nunca ou nunca

$5=$ Muito alto

$4=$ Alto

3 = Moderado

2 = Baixo

1 = Muito baixo ou absolutamente nenhum

$0=$ Sem atividade sexual

5 = Quase sempre ou sempre

4 = A maioria das vezes (mais do que a metade do tempo)

3 = Algumas vezes (cerca de metade do tempo)

2 = Poucas vezes (menos da metade do tempo)

1 = Quase nunca ou nunca

$0=$ Sem atividade sexual

$5=$ Muito alto

$4=$ Alto

3 = Moderado

2 = Baixo

1 = Muito baixo ou absolutamente nenhum

$0=$ Sem atividade sexua

5 = Segurança muito alta

4 = Segurança alta

3 = Segurança moderada

2 = Segurança baixa

1 = Segurança muito baixa ou Sem segurança

$0=$ Sem atividade sexua

5 = Quase sempre ou sempre

4 = A maioria das vezes (mais do que a metade do tempo)

3 = Algumas vezes (cerca de metade do tempo)

2 = Poucas vezes (menos da metade do tempo)

1 = Quase nunca ou nunca

$0=$ Sem atividade sexua

5 = Quase sempre ou sempre

4 = A maioria das vezes (mais do que a metade do tempo)

3 = Algumas vezes (cerca de metade do tempo)

2 = Poucas vezes (menos da metade do tempo)

1 = Quase nunca ou nunca

$0=$ Sem atividade sexual

1 = Extremamente difícil ou impossivel

2 = Muito difícil

$3=$ Difícil

4 = Ligeiramente difícil

$5=$ Nada difícil

(continua) 
Opções de respostas e

pontuação

9- Nas últimas 4 semanas, com que freqüência (quantas vezes) você manteve a lubrificação vaginal (ficou com a "vagina molhada") até o final da atividade ou ato sexual?

10- Nas últimas 4 semanas, qual foi sua dificuldade em manter a lubrificação vaginal ("vagina molhada") até o final da atividade ou ato sexual?

11- Nas últimas 4 semanas, quando teve estímulo sexual ou ato sexual, com que freqüência (quantas vezes) você atingiu o orgasmo ("gozou")?

12 - Nas últimas 4 semanas, quando você teve estímulo sexual ou ato sexual, qual foi sua dificuldade em você atingir o orgasmo ("clímax/gozou")?

13- Nas últimas 4 semanas, o quanto você ficou satisfeita com sua capacidade de atingir o orgasmo ("gozar") durante atividade ou ato sexual?

14- Nas últimas 4 semanas, o quanto você esteve satisfeita com a proximidade emocional entre você e seu parceiro(a) durante a atividade sexual?

15- Nas últimas 4 semanas, o quanto você esteve satisfeita com o relacionamento sexual entre você e seu parceiro(a)?

16- Nas últimas 4 semanas, o quanto você esteve satisfeita com sua vida sexual de um modo geral?
$0=$ Sem atividade sexual

5 = Quase sempre ou sempre

4 = A maioria das vezes (mais do que a metade do tempo)

3 = Algumas vezes (cerca de metade do tempo)

2 = Poucas vezes (menos da metade do tempo)

1 = Quase nunca ou nunca

$0=$ Sem atividade sexual

1 = Extremamente difícil ou impossível

2 = Muito difícil

$3=$ Difícil

4 = Ligeiramente difícil

$5=$ Nada difícil

$0=$ Sem atividade sexual

5 = Quase sempre ou sempre

4 = A maioria das vezes (mais do que a metade do tempo)

3 = Algumas vezes (cerca de metade do tempo)

2 = Poucas vezes (menos da metade do tempo)

1 = Quase nunca ou nunca

$0=$ Sem atividade sexual

1 = Extremamente difícil ou impossível

2 = Muito difícil

$3=$ Difícil

4 = Ligeiramente difícil

5 = Nada difíci

$0=$ Sem atividade sexual

$5=$ Muito satisfeita

4 = Moderadamente satisfeita

3 = Quase igualmente satisfeita e insatisfeita

2 = Moderadamente insatisfeita

1 = Muito insatisfeita

$0=$ Sem atividade sexual

$5=$ Muito satisfeita

4 = Moderadamente satisfeita

3 = Quase igualmente satisfeita e insatisfeita

2 = Moderadamente insatisfeita

$1=$ Muito insatisfeita

$5=$ Muito satisfeita

4 = Moderadamente satisfeita

3 = Quase igualmente satisfeita e insatisfeita

2 = Moderadamente insatisfeita

$1=$ Muito insatisfeita

5 = Muito satisfeita

4 = Moderadamente satisfeita

3 = Quase igualmente satisfeita e insatisfeita

2 = Moderadamente insatisfeita

$1=$ Muito insatisfeita

(continua) 
Tabela 2 (continuação)

\begin{tabular}{|c|c|}
\hline Perguntas & $\begin{array}{l}\text { Opções de respostas e } \\
\text { pontuação }\end{array}$ \\
\hline \multirow{7}{*}{$\begin{array}{l}\text { 17- Nas últimas } 4 \text { semanas, com que freqüência (quantas vezes) } \\
\text { você sentiu desconforto ou dor durante a penetração vaginal? }\end{array}$} & $0=$ Não tentei ter relação \\
\hline & I = Quase sempre ou sempre \\
\hline & $2=$ A maioria das vezes (mais do que a metade \\
\hline & do tempo) \\
\hline & $3=$ Algumas vezes (cerca de metade do tempo) \\
\hline & $4=$ Poucas vezes (menos da metade do tempo) \\
\hline & $5=$ Quase nunca ou nunca \\
\hline \multirow{7}{*}{$\begin{array}{l}\text { 18- Nas últimas } 4 \text { semanas, com que freqüência (quantas vezes) } \\
\text { você sentiu desconforto ou dor após a penetração vaginal? }\end{array}$} & 0 = Não tentei ter relação \\
\hline & 1 = Quase sempre ou sempre \\
\hline & $2=$ A maioria das vezes (mais do que a metade \\
\hline & do tempo) \\
\hline & $3=$ Algumas vezes (cerca de metade do tempo) \\
\hline & $4=$ Poucas vezes (menos da metade do tempo) \\
\hline & $5=$ Quase nunca ou nunca \\
\hline \multirow{6}{*}{$\begin{array}{l}\text { 19- Nas últimas } 4 \text { semanas, como você classificaria seu grau de } \\
\text { desconforto ou dor durante ou após a penetração vaginal? }\end{array}$} & $0=$ Não tentei ter relação \\
\hline & $1=$ Muito alto \\
\hline & $2=$ Alto \\
\hline & $3=$ Moderado \\
\hline & $4=$ Baixo \\
\hline & 5 = Muito baixo ou absolutamente nenhum \\
\hline
\end{tabular}

Instruções:

Este questionário pergunta sobre sua vida sexual durante as últimas 4 semanas. Por favor, responda às questões de forma mais honesta e clara possível. Suas respostas serão mantidas em absoluto sigilo.

Assinale apenas uma alternativa por pergunta.

Para responder às questões use as seguintes definições: atividade sexual pode incluir afagos, carícias preliminares, masturbação ("punheta"/"siririca") e ato sexual; ato sexual é definido quando há penetração (entrada) do pênis na vagina; estímulo sexual inclui situações como carícias preliminares com um parceiro, auto-estimulação (masturbação) ou fantasia sexual (pensamentos); desejo sexual ou interesse sexual é um sentimento que inclui querer ter atividade sexual, sentir-se receptiva a uma iniciativa sexual de um parceiro(a) e pensar ou fantasiar sobre sexo; excitação sexual é uma sensação que inclui aspectos físicos e mentais (pode incluir sensações como calor ou inchaço dos genitais, lubrificação - sentir-se molhada/"vagina molhada"/"tesão vaginal" -, ou contrações musculares).

possível detectar problemas e dificuldades que poderiam ter sido minimizados caso não se observassem todas as fases do processo.

Quanto à avaliação das equivalências idiomática, cultural e conceitual, na Etapa 4, foram julgadas adequadas para a equivalência das versões as modificações propostas de forma que se procurou preservar e adequar tanto equivalência no significado das palavras, quanto na equivalência de expressões, situações culturalmente evocadas pelos termos e manutenção do conceito do instrumento original. Com base nisso, em relação à equivalência de pontuação, o comitê de juízes considerou adequada a conservação da mesma escala de pontuação do instrumento original, dado que não houve inclusão ou retirada de itens presentes no questionário em inglês.
Quanto ao modo de aplicação, estudos posteriores poderão demonstrar se há equivalência. Originalmente o instrumento propõe que seja auto-aplicado; no entanto, em estudos populacionais, essa forma de aplicação do instrumento pode trazer viés de resposta, já que parte considerável de nossa população pode ter dificuldade de leitura dos enunciados. Assim, o modo de aplicação utilizando entrevistas pode ser preferível.

Muito embora as propriedades psicométricas do instrumento original já tenham sido estabelecidas, é necessário determiná-las na versão em português. Embora haja controvérsia a respeito da manutenção das propriedades de medida do instrumento adaptado, visto que alguns autores pressupõem que a adequada adaptação transcultural de um instrumento possa trazer consi- 
go as propriedades de medida do instrumento original, outros autores argumentam que a própria tradução para outro contexto confere propriedades desconhecidas ao instrumento. Nesse sentido, a disponibilização do instrumento para pesquisas só deverá ser feita após a apresentação da análise de suas qualidades de medidas para o Brasil, o que inclui a distribuição dos domínios da resposta sexual. Isso deve ser objeto de estudos próximos.

\section{Resumo}

Ainda hoje pouco se conhece sobre a epidemiologia das disfunções sexuais femininas. O Female Sexual Function Index (FSFI) [Índice de Função Sexual Feminina] é um questionário breve, que pode ser auto-aplicado, $e$ que se propõe avaliar a resposta sexual feminina. Este estudo teve por objetivo avaliar a adaptação transcultural da versão em português do FSFI. O processo envolveu cinco etapas: tradução, versão, apreciação formal de equivalência, revisão crítica por especialistas em sexualidade e pré-teste do instrumento. Após a identificação de problemas semânticos, concordâncias e discordâncias, foi possível propor uma versão sintética, escolhendo e incorporando itens de uma das duas versões em português. Algumas mudanças foram realizadas após o pré-teste do questionário, para tornar a versão em português mais coloquial e aceitável para a população-alvo ao utilizar termos mais corriqueiros, como opção ou complemento à linguagem científica. Ao se comparar mais de uma versão do instrumento, no processo de equivalência transcultural, foi possível detectar problemas e dificuldades na adaptação da linguagem que poderiam ter passado despercebidos, caso não se observassem todas as fases do processo.

Disfunção Sexual Fisiológica; Saúde da Mulher; Questionários

\section{Colaboradores}

R. C. Pacagnella revisou a literatura, participou do desenho do estudo, do pré-teste do questionário, da análise dos dados e da elaboração deste artigo. E. M. Vieira orientou o desenho do estudo, a análise de dados, o préteste do instrumento, fez revisão crítica dos resultados e elaboração deste artigo. O. M. Rodrigues Jr. e C. Souza participaram da discussão dos resultados na análise dos dados e da elaboração deste artigo. 


\section{Referências}

1. Loyola MA. Sexualidade e medicina: a revolução do século XX. Cad Saúde Pública 2003; 19:875-99.

2. Citeli MT. A pesquisa sobre sexualidade e direitos sexuais no Brasil (1990-2002): revisão crítica. Rio de Janeiro: Centro de Estudos e Pesquisa em Saúde Coletiva; 2005.

3. Canesqui AM. Os estudos de antropologia da saúde/doença no Brasil na década de 1990. Ciênc Saúde Coletiva 2003; 8:109-24.

4. Althof SE, Rosen RC, Derogatis L, Corty E, Quirk F, Symonds T. Outcome measurement in female sexual dysfunction clinical trials: review and recommendations. J Sex Marital Ther 2005; 31:153-66.

5. Lauman EO, Paik A, Rosen RC. Sexual dysfunction in the United States: prevalence and predictors. JAMA 1999; 281:537-44.

6. Rosen RC. Assessment of female sexual dysfunction: review of validates methods. Fertil Steril 2002; 77:S89-93.

7. Basson R, Berman J, Burnett A, Derogatis L, Ferguson D, Fourcroy J, et al. Report of the International consensus development conference on female sexual dysfunction: definitions and classifications. J Urol 2000; 163:888-94.

8. Master WH, Johnson VE. Human sexual response. Boston: Little Brown; 1966.

9. Tiefer L, Hall M, Tavris C. Beyond dysfunction: a new view of women's sexual problems. J Sex Marital Ther 2002; 28:225-32.

10. Wiegel M, Meston C, Rosen R. The Female Sexual Function Index (FSFI): cross-validation and development of clinical cutoff scores. J Sex Marital Ther 2005; 31:1-20.

11. Basson R, Leiblum S, Brotto L, Derogatis L, Fourcroy J, Fugl-Meyer K, et al. Revised definitions of women's sexual dysfunction. J Sex Med 2004; 1:40.

12. Pasqualotto EB, Pasqualotto FF, Sobreiro BP, Lucon AM. Female sexual dysfunction: the important points to remember. Clinics 2005; 60:51-60.

13. Daker-White G. Reliable and valid self-report outcome measures in sexual (dys)function: a systematic review. Arch Sex Behav 2002; 31:197-209.

14. Basson R, McInnes R, Smith MD, Hodgson G, Koppiker N. Efficacy and safety of sildenafil citrate in women with sexual dysfunction associated with female sexual arousal disorder. J Womens Health Gend Based Med 2002; 11:367-77.

15. Basson R. Are our definitions of women's desire, arousal and sexual pain disorders too broad and our definitions of orgasmic disorders too narrow. J Sex Marital Ther 2002; 28:289-300.

16. Rodrigues Jr. OM. Inventários de sexualidade - uma forma de obtenção de conhecimento complementar da vida sexual. Terapia Sexual 1999; $1: 77-84$
17. Rosen RC, Brown C, Heiman J, Leiblum S, Meston CM, Shabsigh R, et al. The Female Sexual Function Index (FSFI): a multidimensinal self-report instrument for the assessment of female sexual function. J Sex Marital Ther 2000; 26:191-208.

18. Ciconelli RM. Medidas de avaliação de qualidade de vida. Rev Bras Reumatol 2003; 43:IX-XIII.

19. Taylor JE, Rosen RC, Leiblum SR. Self-report assessment of female sexual function: psychometric evaluation of the Brief Index of Sexual Functioning for Women (BISF-W). Arch Sex Behav 1994; 23:62743.

20. Quirk FH, Heiman J, Rosen R, Laane E, Smith M, Boolell M. Development of a sexual function questionnaire for clinical trials of female sexual dysfunction. J Womens Health Gend Based Med 2002; 11:331-3.

21. Rellini A, Meston C. The sensitivity of event logs, self-administered questionnaires and photoplethysmography to detect treatment-induced changes in female sexual arousal disorder (FSAD) diagnosis. J Sex Med 2006; 3:283-91.

22. Abdo CHN, Moreira JR, Fittipaldi JAS. Estudo do comportamento sexual no Brasil - ECOS. Rev Bras Med 2000; 57:1329-35.

23. Meston C. Validation of the Female Sexual Function Index (FSFI) in women with female orgasmic disorder and in women with hypoactive sexual desire disorder. J Sex Marital Ther 2003; 29:39-46.

24. Guillemin F, Bombardier C, Beaton D. Cross-cultural adaptation of health-related quality of life measures: literature review and proposed guidelines. J Clin Epidemiol 1993; 46:1417-32.

25. Falcão DM, Ciconelli RM, Ferraz MB. Translation and cultural adaptation of quality of life questionnaires: an evaluation of methodology. J Rheumatol 2003; 30:379-85.

26. Reichenheim ME, Moraes CL, Hasselmann MH. Equivalência semântica do instrumento Abuse Assessment Screening. Rev Saúde Pública 2000; 34:610-6.

27. Herman M, Fox-Rushby J, Badia X. "Equivalence" and the translation and adaptation of Health-Related Quality of Life Questionnaires. Qual Life Res 1997; 6:237-47.

28. Jorge MR. Adaptação transcultural de instrumentos de pesquisa em saúde mental. Rev Psiquiatr Clín (São Paulo) 1998; 25:233-9.

29. Ferraz BM, Ciconelli RM. Tradução e adaptação do índice internacional de função erétil para a língua portuguesa. Rev Bras Med 1998; 55:35-40.

30. Moraes CL, Hasselmann MH, Reichenheim ME. Adaptação transcultural para o português do instrumento "Revised Conflict Tactics Scales (CTS2)" utilizado para identificar violência entre casais. Cad Saúde Pública 2002; 18:163-76.

Recebido em 20/Out/2006

Versão final reapresentada em 11/Jul/2007

Aprovado em 24/Ago/2007 